\title{
A GESTÃO DO NEGÓCIO TURÍSTICO APOIADO NA CAPACITAÇÃO PROFISSIONAL E NA QUALIDADE DO ATENDIMENTO AO CLIENTE
}

\section{THE MANAGEMENT OF THE TOURIST BUSINESS SUPPORTED IN THE PROFESSIONAL AND THE QUALITY OF CUSTOMER SERVICE}

\author{
Data do recebimento do artigo: 15/11/2012 \\ Data do aceite do artigo: 4/3/2013 \\ Data da publicação: 10/6/2013
}

\author{
Liliane Azevedo Santaella ${ }^{1}$ \\ Mestre em Gestão e Desenvolvimento Regional \\ Universidade de Taubaté - UNITAU \\ Jorge Luiz Knupp Rodrigues \\ Doutor em Educação (Currículo) - PUC-SP \\ Professor do Mestrado em Gestão e Desenvolvimento Regional \\ Universidade de Taubaté - UNITAU
}

\section{RESUMO}

O negócio turístico é um dos maiores geradores de benefícios para o País e para as comunidades locais, como podemos ver por meio da história. Porém, para que o este negócio agregue valor as pessoas, as organizações e as comunidades necessitam alinhar-se às características e necessidades do contexto atual. O século XXI acena para uma sociedade baseada no conhecimento, com pessoas treinadas e capacitadas para tomadas de decisões, isto é, com competências que agreguem valor ao negócio.

Palavras chave: Turismo. Negócio Turístico. Qualidade no Atendimento. Capacitação Profissional. Mudanças.

\begin{abstract}
The tourist business is one of the generating greaters of benefits for the Country and the local communities, as we can see through history. However, so that this business adds value the people and the organizations it is necessary to line up the characteristics and necessities of the current context. Century XXI waves for a society based on the knowledge, with people trained and enabled to taking of decisions, that is, with abilities that add value to the business.
\end{abstract}

\footnotetext{
${ }^{1}$ Autor para correspondência: Universidade de Taubaté - Rua Expedicionário Ernesto Pereira, 225, Portão 2, CEP 12020-030, Taubaté, SP, Brasil.
} 
Keywords: Tourism. Tourist business. Quality in the Attendance. Professional qualification. Changes. 


\section{INTRODUÇÃO}

A expansão das atividades relacionadas ao turismo tem sido grande no Brasil e no mundo. $\mathrm{O}$ crescimento do turismo mundial se destaca principalmente nos países considerados emergentes, que vêm apresentando um crescimento de $6 \%$ a $8 \%$, frente aos países industrializados, desenhando um caminho em busca de um crescimento econômico sustentável (OMT, 2008).

Novas tendências, originadas da segmentação das modalidades do turismo, também estão contribuindo para o crescimento do setor, abrindo um leque de atividades interdependentes. Desse modo, as dimensões do turismo tornam-se cada vez mais amplas, abrangendo diversas destinações e envolvendo mais comunidades e locais, que até aparentemente inexpressivos, adquirem, muitas vezes, grande importância turística por suas peculiaridades e atrativos, afirma Rodrigues (2004).

Algumas localidades para serem reconhecidas como um atrativo turístico precisam dar um enorme salto de qualidade, principalmente, no que diz respeito a infraestrutura, preparação da comunidade, pois a atividade turística pode odificar radicalmente alguns paradigmas locais.

\footnotetext{
Para que um local seja reconhecimento como um local turístico, o que não é um processo natural, pois depende de uma construção cultural, envolvendo a criação de um sistema integrado de significados, através dos quais a realidade turística de um lugar é estabelecida, mantida e negociada (CASTRO, 1999).
}

O desenvolvimento de atividades ligadas ao turismo tem estimulado a descoberta de novos destinos e aproveitados como locais de potencial turísticos, gerando novas atividades, oportunidades de trabalho e o desenvolvimento local e regional. Da mesma forma, pólos receptores já consagrados continuam se desenvolvendo e incrementando-se para melhor atender às necessidades e expectativas dos visitantes.

Portanto, é preciso agregar valores as riquezas naturais ou artificiais, para que estas sejam exploradas de forma adequada para a captação de recursos, inclusive financeiros, tanto para o empreendedor, como para a população local que se desenvolve econômica e socialmente com a sua prática, em seu local de origem. Porém, para que todos se beneficiem com as atividades ligadas ao Turismo é necessário uma maior capacitação das pessoas e uma maior preocupação com a qualidade no atendimento ao cliente.

\section{METODOLOGIA}

O presente artigo baseia-se em uma pesquisa que pode ser classificada como pesquisa explicativa que, segundo Gil (2007) é o tipo de pesquisa que mais aprofunda o conhecimento da realidade, porque explica a razão, o porquê das coisas. Utilizou-se também a pesquisa bibliográfica que de acordo com Vergara (2005) caracteriza-se pelo estudo sistematizado, 
desenvolvido com base em material publicado em livros, teses, dissertações, revistas, redes eletrônicas, isto é, material acessível ao público em geral. Ainda segundo a autora, a pesquisa bibliográfica fornece instrumental analítico para qualquer outro tipo de pesquisa, mas também pode esgotar-se em si mesma, como no caso do presente estudo. Além disso, utilizou-se uma pesquisa de campo que segundo Vergara (2005) é uma investigação empírica realizada por meio de entrevistas, aplicação de questionários, testes e observação participante, ou não, no local onde ocorre, ou ocorreu um fenômeno.

\section{O TURISMO NO BRASIL}

O Brasil é um País com grande potencial natural e cultural para a prática do turismo. Só para ilustrar no ano de 2012, deram entrada no País 5,7 milhões de turistas (OMT, 2013). É preciso agregar valores a essa riqueza, para que a atividade seja explorada de forma adequada, captando recursos financeiros tanto para o empreendedor como para a população local que se desenvolve econômica e socialmente com a sua prática no País, mais respectivamente em seu local de origem.

De maneira geral encontramos vários entraves para o desenvolvimento do turismo no Brasil, dentre eles a falta de formatação de produtos turísticos, a falta de capacitação profissional, a pouca preocupação com a qualidade no atendimento ao turista, a falta de infra estrutura adequada, os problemas relacionados a segurança pública. No Brasil, em função do potencial do País, o turismo vem desde a década de 1970, como defendem Zouain e Cruz (2004, p. 40), sendo apontado como:

uma alternativa viável e importante para o desenvolvimento econômico, capaz de representar uma opção estratégica para reduzir graves problemas sociais. Entretanto, ainda segundo esses autores, a expectativa de desenvolvimento não tem se confirmado e, com frequência tem gerado grandes retrocessos em termos de desenvolvimento social.

A expansão das atividades relacionadas ao turismo tem sido grande no Brasil e no mundo. Novos destinos são continuamente descobertos e aproveitados como locais de potencial turísticos, gerando novas atividades, oportunidades de trabalho e o desenvolvimento local e regional. Da mesma forma, pólos receptores já consagrados continuam se desenvolvendo e incrementando-se para melhor atender às necessidades e expectativas dos visitantes.

Novas tendências, originadas da segmentação das modalidades do turismo, também têm contribuído significativamente para o crescimento do setor, abrindo um leque de atividades interdependentes. Desse modo, as dimensões do turismo tornam-se cada vez mais amplas, abrangendo diversas destinações e envolvendo mais comunidades e locais, até aparentemente inexpressivas, adquirem, às vezes, grande importância turística pelas suas peculiaridades e atrativos. 


\section{A CAPACITAÇÃO PROFISSIONAL}

O interesse pela capacitação e qualificação profissional de membros de uma sociedade não é absolutamente novo. De uma maneira geral, podemos notar que o interesse pela capacitação e qualificação profissional, está presente desde o momento em que se instaurou a divisão social do trabalho e, com esta, gradativamente, a divisão técnica do trabalho. As exigências do mundo do trabalho, em nível de qualificações e de competências, a socialização do saber e a posse de informações a curto prazo exigem a ampliação e diversificação das alternativas educacionais, bem como, a sua sintonia com as transformações tecnológicas (MATA, 2001).

A falta de capacitação dos empregados dificulta o desenvolvimento de competências dos mesmos e coloca o indivíduo na contra mão da história. A ótica empresarial tem sido dar ênfase à qualificação de recursos humanos, valorizando cada vez mais os conhecimentos produzidos nos diferentes campos, a polivalência, a flexibilidade, a produtividade e a qualidade do trabalho.

(...) el mundo del trabajo se ha apropiado de la noción de competencia, la escuela estaría siguiendo sus pasos, bajo el pretexto de modernizarse y de insertarse en la corriente de los valores de la economía del mercado, como la gestión de recursos humanos; la búsqueda de la calidad total; la valoración de la excelencia; la mayor exigencia; y una mayor movilidad de los trabajadores y de la organización del trabajo (PERRENOUD, 2002, p. 47).

Observa-se que o crescimento dos conhecimentos científicos e técnicos tem se tornado cada vez mais ágeis não pertencendo mais apenas a pequenos grupos, pois a construção e desenvolvimento dos mesmos são realizadas por meio da troca e da interação entre os indivíduos. Para Masetto (2003), as carreiras estão sendo repensadas baseando-se em novas capacidades e formação continuada dos profissionais, bem como novas capacitações, por exemplo, adaptabilidade ao novo, criatividade, autonomia, comunicação, iniciativa, cooperação.

Mesmo observando-se o surgimento de novos negócios turísticos e a crescente oferta de vagas nos mais diferentes cargos, principalmente nas redes hoteleiras, os empregadores reclamam da carência de mão-de-obra qualificada, afirmam Nakamura (2003) e Amaral (2003). A escolaridade das pessoas disponíveis para funções operacionais é baixa e para os cargos gerenciais é incompleta.

Como agravante, há grande carência de profissionais multifuncionais no mercado. O turismo, pela sua especificidade, é mais que um negócio, um processo ou uma atividade geradora de impactos. Além disso, muitos empresários da área não investem na capacitação de seus empregados, pois acreditam que isto é um custo para eles. Veja os dados na Figura 1 obtidos na pesquisa de Rodrigues (2010), no Litoral Norte do Estado de São Paulo, demonstram que nas empresas pesquisadas um percentual muito pequeno do faturamento destas empresas é investido em capacitação dos seus empregados. 


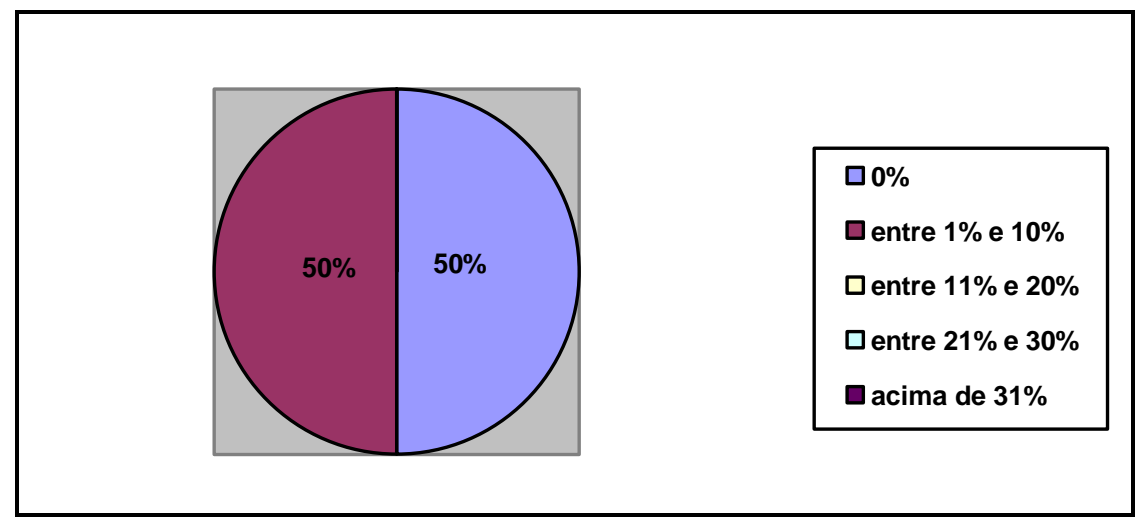

Figura 1: Percentual do faturamento dedicado a capacitação/ treinamento dos empregados.

Fonte: Rodrigues (2010)

Devido o crescimento do turismo no Brasil a estimativa de geração de novos empregos é grande devido ao aumento de demanda, porém o profissional que o mercado espera deve ser preparado para a função. Além de possuir algumas características pessoais, deve ter no mínimo, o domínio de dois idiomas e um curso superior na área e para que possa contribuir com a busca de resultados da organização na qual trabalha.

Senge (2005) afirma que nos mercados extremamente competitivos e complexos no qual as empresas operam, só existe espaço para as organizações que criam um ambiente para impulsionar o compromisso do seu pessoal com a mudança, e que, seja capaz de mantê-lo sempre ativo. O autor afirma também, que neste contexto não é possível considerar as pessoas como se fossem máquinas.

Como sabemos, o alto potencial turístico brasileiro está atraindo turistas e investidores de várias partes do mundo. Os primeiros querem conhecer as belezas naturais do Brasil, enquanto os empresários do setor exploram os novos nichos do mercado. Chegou, então, o momento de o turismo ser encarado como uma atividade econômica, fomentadora de emprego, renda e divisas.

Para Pretti (2000) as rápidas transformações econômicas requerem uma formação técnicocientífica básica e o acesso a um saber universalizante. Na pesquisa realizada por Rodrigues (2010) foi constatado que a maioria das empresas não possuía uma área específica para a capacitação dos empregados, isto demonstra a falta de preocupação com o processo de capacitação dos empregados, como podemos ver nas respostas demonstradas na Figura 2. 


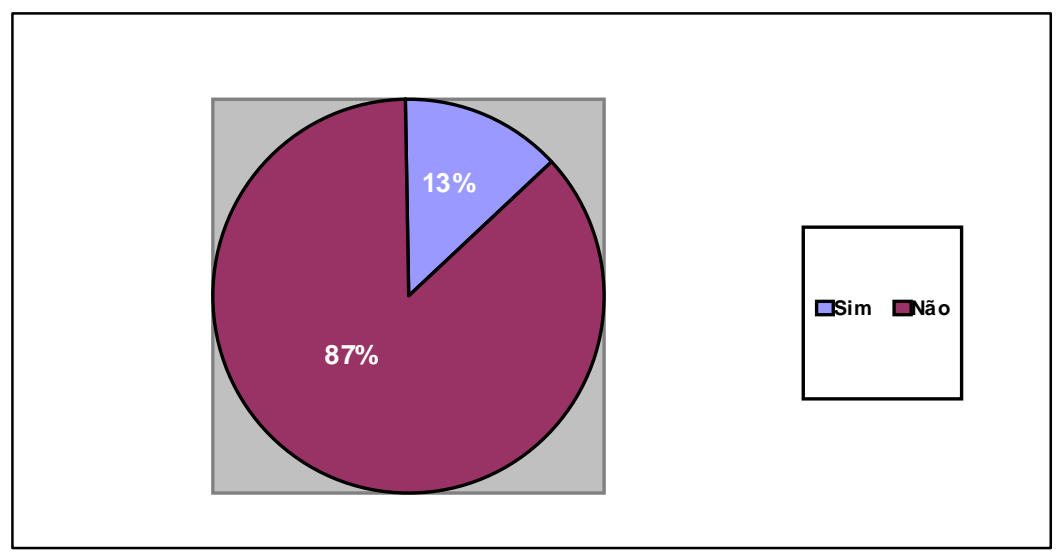

Figura 2: Existência de área responsável pelos processos de capacitação /treinamento dos empregados nas empresas.

Fonte: Rodrigues (2010)

No litoral Norte Paulista, os problemas parecem ter início já no recrutamento, pois o mesmo é realizado de maneira amadora, buscando pessoas conhecidas ou aquelas que estão mais perto da organização. Posteriormente, passando pela seleção das pessoas que muitas vezes é feita de maneira informal e sem critério profissionais definidos e também nas formas de remuneração que em $86 \%$ das empresas pesquisadas refletem o piso da categoria e $14 \%$ possuem alguma gratificação a mais. A concessão de benefícios também parece não atrair profissionais adequados por não serem estimulantes ou não existirem, e alguns casos até o registro em carteira é considerado benefício. Isto também pode ser observado nos dados da pesquisa de Rodrigues (2100), conforme retratado no Figura 3.

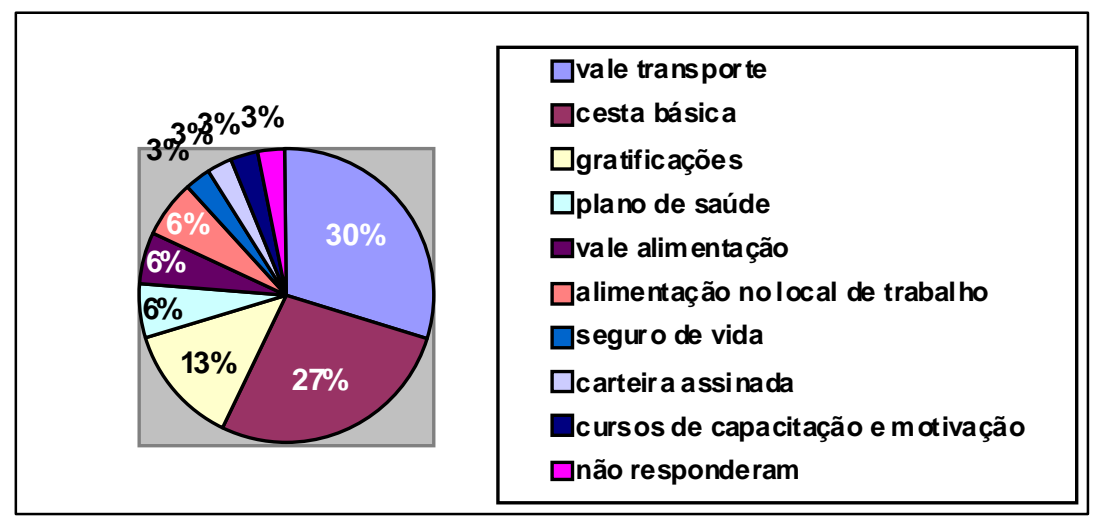

Figura 3: Benefícios concedidos aos trabalhadores Fonte: Rodrigues (2010) 
Para completar esta deficiência, encontramos ainda organizações e proprietários que acreditam que capacitação/treinamento é responsabilidade do poder público e ou do próprio indivíduo, o que parece demonstrar uma confusão entre a educação necessária as pessoas e o treinamento das mesmas. Os dados da pesquisa realizada por Rodrigues (2010) e que demonstram a visão da empresa sobre os responsáveis pelo processo de capacitação do empregado estão no Figura 4.

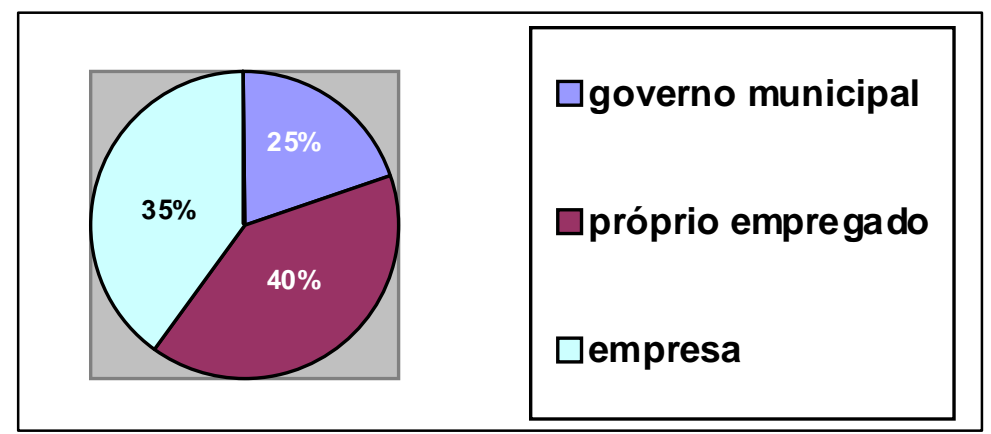

Figura 4: Visão da organização sobre a responsabilidade do processo de capacitação/treinamento do empregado.

Fonte: Rodrigues (2010)

Outro dado que parece demonstrar pouco interesse das empresas pelo processo de capacitação de seus empregados é a carga horária destinada as atividades deste processo, observada também na pesquisa realizada por Rodrigues (2010) e demonstrada no Figura 5.

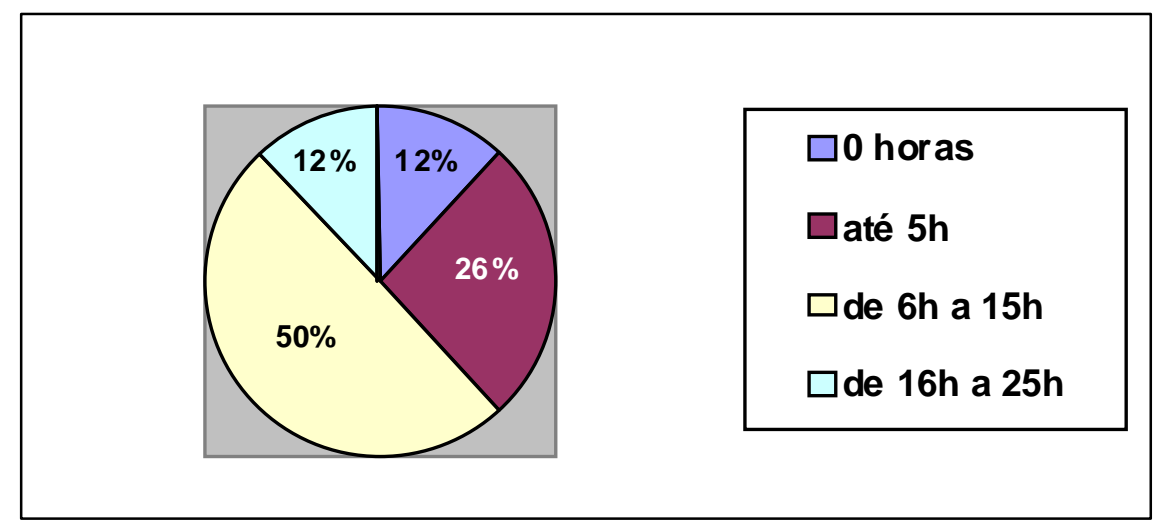

Figura 5: Número de horas mensais destinadas a cada empregado para capacitação /treinamento

Fonte: Rodrigues (2010) 
Já com relação a periodicidade e os motivos que levam as empresas encaminharem seus funcionários para capacitação podemos ver na pesquisa realizada por Rodrigues (2010) que na maioria das empresas não existe um planejamento para atendimento das necessidades de capacitação e sim quando da ocorrência de eventos, alguns funcionários participam, Figura 6.

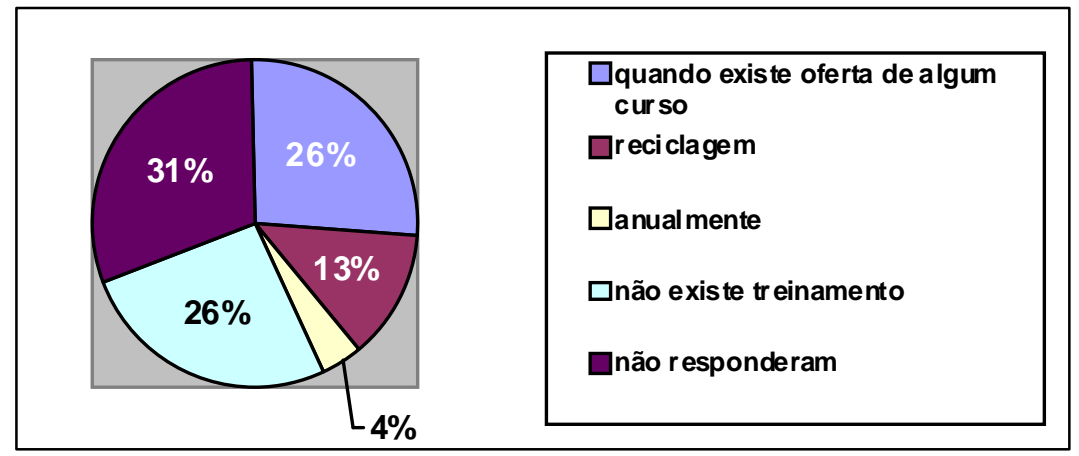

Figura 6: Periodicidade e motivos que fazem com que as organizações encaminhem seus empregados para processos de capacitação/treinamento Fonte: Rodrigues (2010)

Parece importante destacar também que a atividade turística envolve pessoas com níveis culturais e sociais por vezes muito distintos e que interagem nas diversas etapas do produto turístico. Assim sendo, existe um alto grau de interatividade do cliente ou turista, com todos os responsáveis pelo produto turístico vendido, desde o frentista do posto de gasolina, do farmacêutico e do bancário, até o guia turístico, o recepcionista e a aeromoça. Essa multiplicidade de contatos do fabricante com o consumidor, em tantas e diferentes etapas torna a atividade turística muito complexa. Mais complexa ainda, se considerarmos que em todas as etapas existem seres humanos envolvidos e, que cada erro, por mais simples que seja, é percebido e comentado, na maioria das vezes, "em tempo real" pelos consumidores.

\section{A QUALIDADE NO ATENDIMENTO}

A capacitação dos Recursos Humanos, a eliminação de desperdícios e a preocupação com a qualidade no atendimento devem fazer parte das preocupações constantes de qualquer organização, principalmente aquelas voltadas ao Turismo. Com a abertura cada vez mais crescente do mercado brasileiro, fruto da globalização, nenhuma organização pode se dar ao luxo de conduzir o seu negócio baseado em antigos e amadores métodos de administração.

A revolução da qualidade invadiu o nosso País. Os consumidores estão cada vez mais exigentes, buscando produtos que ofereçam, simultaneamente, qualidade e preço baixo. Por este e outros motivos, as organizações juntaram-se à revolução da qualidade total ou deverão juntar-se, caso contrário sucumbirão, arrasadas pela concorrência global. 
O turismo é uma atividade econômica de prestação de serviços, que tem nos recursos humanos o seu principal elemento. $\mathrm{O}$ bom atendimento ao turista é o principal fator de avaliação do produto e existem localidades com enorme potencial turístico que não conseguem decolar seu desenvolvimento pela ausência de investimentos em capacitação de recursos humanos. O turismo depende de uma infinidade de serviços especializados, os quais, por sua vez, dependem de uma infinidade de profissionais com as mais variadas especializações, segundo Ignara (2003, p.72).

A necessária competitividade é operacionalizada dentro das organizações através dos princípios, técnicas e metodologias da área de qualidade, a qual se harmoniza perfeitamente com as duas grandes tendências desta nova ordem: visão holística e valorização do ser humano. A gestão pela qualidade está diretamente relacionada com todos os outros sistemas de gestão na busca de soluções coerentes com os macro-objetivos das organizações, abrangendo todos os níveis hierárquicos.

Tendo como um de seus princípios básicos a focalização nas necessidades do cliente. A gestão pela qualidade conduz a organização como um todo, a um processo de melhoria contínua e integrada, em direção ao cumprimento de sua missão. Assim sendo, a organização deverá desenvolver novas atitudes, valores e objetivos, dentre eles os que estão presentes nos princípios de Total satisfação dos clientes, Desenvolvimento de Recursos Humanos, Gerência, Constância de propósitos, Aperfeiçoamento contínuo, Gerência de processos, Delegação, Disseminação de informações, Não-aceitação de erros e Garantia da qualidade.

\begin{abstract}
Na sociedade contemporânea, as grandes transformações no mundo do trabalho, o avanço tecnológico configurando a sociedade virtual e os meios de informação e comunicação exercem uma força enorme nas relações sociais e em todas as instituições de nossa sociedade, exigindo delas um reposicionamento e a busca de um novo perfil frente aos desafios do que tem se chamado de pós-modernidade. $\mathrm{O}$ acelerado desenvolvimento tecnológico e cultural bem como as mudanças percebidas em todas as áreas do conhecimento estão caracterizados por uma complexa variedade de processos, movidos por uma mistura de influências políticas e econômicas, por novos sistemas e novas forças internas e principalmente externas ao País (RODRIGUES, 2006, p.11).
\end{abstract}

A qualidade de qualquer coisa ou pessoa é definida em relação a um conjunto de valores referenciais estabelecidos socialmente. A sociedade contemporânea, fundamentada na produção e consumo de mercadorias, engendrou uma cultura da realização humana pelo consumo. De alguma forma, a realização coincide com a capacidade de consumo e a satisfação com a maneira como essa capacidade se viabiliza. A satisfação é aferida por duas variáveis: a primeira diz respeito às características intrínsecas do objeto de consumo e a segunda ao próprio processo de consumo.

As duas variáveis estão em permanente mutação, pois encontram-se submetidas ao desenvolvimento técnico e organizacional da produção de mercadorias, que cria, de forma frenética, novos produtos e as correspondentes necessidades de consumo. Esse desenvolvimento também atualiza a cada instante as maneiras como se realiza o consumo. Por conseqüência, o 
conjunto de valores referenciais utilizados na definição de qualidade está também em permanente mudança. Juran e Gryna (1991, p.11) afirmam que a "qualidade consiste nas características do produto que vão ao encontro das necessidades dos clientes e dessa forma proporcionam a satisfação em relação ao produto. (...) A qualidade é a ausência de falhas”.

\begin{abstract}
A qualidade tem sido um conceito que se altera ao longo do tempo. De fato, a fixação da qualidade já enfatizou, por exemplo, o próprio produto, concentrando esforços na forma como ele é apresentado ao consumidor. Era a época em que a inspeção de produtos acabados parecia ser o elemento básico da qualidade, conforme Paladini (2000, pág.82).
\end{abstract}

Dependendo da fonte de pesquisa podemos encontrar vários conceitos de qualidade, como por exemplo, para a ABNT - Associação Brasileira de Normas Técnicas, descrito na norma NBR ISO 8402 encontramos que qualidade é a totalidade de propriedades e características de um produto ou serviço, que confere sua habilidade em satisfazer necessidades explícitas ou implícitas. Já para Juran (1990) qualidade é adequação do produto ou serviço ao uso, ou seja, à necessidade do consumidor.

Segundo Crosby (1990) qualidade é fazer bem desde a primeira vez, isto significa manter um compromisso real com aquilo que está sendo realizado. Já Taguchi (1990) afirma que a qualidade está relacionada à satisfação do cliente, sendo considerada a inovação como uma das etapas básicas para o desenvolvimento da mesma. Falconi (1992) defende que o verdadeiro critério para boa qualidade é a preferência do consumidor em relação ao concorrente uma vez que isso garantirá a sobrevivência da empresa.

Tschohl e Franzmeier (1996, p.10) afirmam que, serviço com qualidade é tudo quanto seus clientes pensam que é, ou seja, é tudo quanto seu cliente deseja. Já observando a ISO 9000/2000 encontramos qualidade como o cumprimento de acordos. Segundo Juran e Gryna (1991) a qualidade é uma função que deve estar presente em todos os departamentos de uma determinada organização, isto é, todas as áreas da empresa devem estar orientadas para a realização de produtos ou serviços adequados ao uso e às necessidades de seus clientes internos ou externos. Segundo Heckert e Silva (2008, p. 321), "a avaliação da qualidade depende muito mais dos valores atribuídos pelo cliente do que das características intrínsecas do produto ou serviço".

A preocupação com qualidade e a implantação de processos de melhoria podem contribuir para a modificação de alguns números apresentados nas estatísticas nacionais e internacionais, apresentadas no site da Central do Consumidor/CC, tais como: $68 \%$ dos clientes consideram o atendimento fundamental ou muito importante em qualquer estabelecimento (INSTITUTO FUTURA Apud CC, 2012). Clientes consideram bom atendimento 8\% mais importante do que preço, pagando até $16 \%$ a mais por serviços de qualidade (TECHNICAL ASSISTANCE PROJECT OF WASHINGTON Apud CC, 2012).

Cerca de $98 \%$ dos clientes retornam às lojas em que foram bem atendidos (INSTITUTO FUTURA Apud CC, 2012). 93\% da comunicação face-a-face advêm da expressão corporal e do tom de voz; apenas 7\% advêm das palavras (USA Apud CC, 2012). 30\% dos clientes desligam o 
telefone quando são atendidos por sistemas automáticos (U.S. MESSAGE CORPORATION Apud CC, 2012). 68\% dos clientes vão embora da empresa devido ao tratamento apático dos funcionários (USA Apud CC, 2012). 49\% dos clientes não têm o hábito de reclamar (ABA Apud CC, 2012).

Um cliente insatisfeito comenta com 11 a 12 conhecidos sobre sua experiência negativa (USA Apud CC, 2012). 90\% dos clientes insatisfeitos com uma empresa nunca mais a procurarão (USA Apud CC, 2012). 65\% dos negócios de uma empresa provêm de seus clientes atuais (AMERICAN MANAGEMENT ASSOCIATION Apud CC, 2012). Conquistar um novo cliente custa cinco vezes mais do que manter um atual (TMI Apud CC, 2012).

Porém, ter qualidade não é apenas satisfazer o cliente, nem tampouco possuir certificação ISO. É necessário encantar sempre mais o cliente a um custo cada vez mais baixo e sempre em menor prazo, e aqueles provedores que não o fizerem não terão a menor chance de sobrevivência. Um dos principais ingredientes para uma gestão profícua da qualidade é a estimular o desenvolvimento das competências necessárias dos indivíduos para que consigam desenvolver suas atividades de forma adequada para a identificação, quantificação e eliminação dos desperdícios através da melhoria contínua dos processos.

As pessoas envolvidas com os processos acostumam-se aos desperdícios e não conseguem enxergá-los, muitas vezes por desenvolverem trabalhos para os quais não foram preparados e não tem competências técnicas, humanas e nem políticas. Independente da organização, do produto ou serviço e do processo as organizações em geral e principalmente aquelas ligadas ao Turismo necessitam conhecer e aplicar um desses conceitos de qualidade, para que consigam traze satisfação aos seus clientes.

Segundo Walker (1991), os clientes representam a alma de todas as organizações. No entanto, poucas empresas parecem dispostas a fazer com que seu desempenho atenda às necessidades de seus clientes, seja em qualidade, eficiência ou pessoal de serviços. Os gestores e empresários precisam reconhecer que a melhoria da qualidade para seus clientes não é uma questão de escolha, a saúde da organização depende disso.

\footnotetext{
O cliente satisfeito não pedirá reparações, pois a transação em particular atendeu a seus anseios. Entretanto, o cliente meramente satisfeito não voltará necessariamente, não se tornará um cliente fiel e na maioria das vezes não se transformará num entusiasmado "vendedor" do serviço, afirmam Corrêa e Caon (2006, p. 91).
}

Com as várias opções de mercado, um dos frutos da globalização, que tem contribuído para a diversificação de produtos e serviços, o cliente, tornou-se infiel, deixando de lado o aspecto preço e se dedicando mais à comodidade e atenções. O diferencial atualmente está centrado no atendimento aos clientes internos e externos, pois são eles que irão divulgar sua marca ao mercado. 
Colocar o cliente em primeiro lugar é uma intenção louvável, mas só conseguirá ser algo mais do que isso se houver uma estratégia de serviços apropriada. Os dois objetivos desta estratégia são: a criação de uma diferença que seja "observável” ou "mensurável” pelos clientes e a obtenção de um impacto verdadeiro na maneira como as coisas são feitas dentro da empresa (WALKER, 1991, p.06).

Outro ponto é a importância de medir a satisfação dos clientes através de pesquisas com o intuito de solucionar os problemas com a própria equipe de trabalho. Medir a qualidade do produto é relativamente fácil, mas a dos serviços é um pouco mais complexo por não ser palpável e basicamente é conquistada através das pessoas. É importante aprender a tratar o cliente como parceiro, amigo e até mesmo como se fosse um sócio. Além de treinar, a organização precisa optar pela qualidade e não quantidade. Ouvir funcionários e fornecedores, também é considerado aspectos de grande importância na tentativa de superar as expectativas do cliente.

A qualidade dos serviços oferecidos ao turista é um dos principais fatores de avaliação do produto turístico. Porém, por meio dos dados da pesquisa de Rodrigues et.al. (2004), verifica-se que as organizações do Litoral Norte Paulista do setor de turismo, pesquisadas, não apresentavam bom índice de qualidade dos serviços oferecidos aos clientes, conforme demonstrado na figura 7.

\begin{tabular}{|l|c|c|c|c|}
\hline Organiz/Qualidade & ótima & boa & satisfatória & ruim \\
\hline Hoteis & $2 \%$ & $25 \%$ & $25 \%$ & $48 \%$ \\
\hline Restaurante & $2 \%$ & $25 \%$ & $35 \%$ & $38 \%$ \\
\hline Pousadas & $4 \%$ & $29 \%$ & $25 \%$ & $42 \%$ \\
\hline Bancos & $2 \%$ & $25 \%$ & $29 \%$ & $44 \%$ \\
\hline Comércio em geral & $3 \%$ & $29 \%$ & $32 \%$ & $36 \%$ \\
\hline
\end{tabular}

Figura 7 - Classificação do nível qualidade segundo os clientes Fonte: Rodrigues et.al. (2004)

Observa-se pelo resultado demonstrado na Figura 7 que há necessidade de mudanças na gestão dos empreendimentos do setor de turismo, com finalidade de melhorar a qualidade do atendimento aos turistas, por meio de programas de qualificação e o incremento de algumas práticas necessárias.

A organização deve também atentar para alguns pontos considerados básicos para a excelência no atendimento ao cliente, como conhecer e escutar os clientes, pensar e acreditar que o atendimento ao cliente traz lucros, treinar e fortalecer os funcionários, elogiar, reconhecer e valorizar as realizações de seu pessoal com freqüência, eliminar todos os procedimentos que não sejam bons para seu relacionamento com os clientes, a cultura da organização deve ser totalmente fanática com relação ao atendimento ao cliente, melhorar continuamente os seus níveis de atendimento, lembrar-se de que todos têm clientes.

Como já dissemos anteriormente o Turismo é uma atividade de serviço, e segundo Lobos (1993, p.66), a qualidade em serviços é antecipar, atender e exceder continuamente os requisitos 
e as expectativas dos clientes. Segundo a análise do referido autor, a qualidade de um serviço está relacionada a três fatores: a) desempenho - que é a razão do serviço em si; b) atendimento - que são os aspectos referentes ao ato da prestação o serviço; c) custo - que é quanto é pago pelo serviço.

\section{CONSIDERAÇÕES FINAIS}

O Turismo nos últimos anos é visto como uma das melhores alternativas de desenvolvimento econômico para cidades, regiões e países, enfatizando-se, sobretudo, a dinamicidade e o potencial de crescimento que o setor apresenta mundialmente. As vantagens desta atividade em termos de geração de emprego e renda a um custo relativamente baixo é o fato de ser considerado uma indústria sem chaminés, relativamente pouco poluidora e com potencial para ajudar a preservar o meio-ambiente.

Embora possa desencadear essas e outras vantagens, o turismo não pode ser estimulado cegamente. Quando o turismo é desenvolvido sem levar em consideração devidamente o contexto em que opera e sem o adequado planejamento e adoção de ações estratégicas ajustadas a esse contexto, como por exemplo, pouca preocupação com a capacitação dos envolvidos, com a qualidade no atendimento ao cliente e com o meio ambiente, pode haver o comprometimento da sustentabilidade da atividade.

O gerenciamento da qualidade das atividades do turismo, especialmente aquelas ligadas ao atendimento ao turista, está diretamente relacionado aos resultados que o provedor irá obter e dependerá de algumas variáveis como a excelência da performance, a satisfação do cliente, o gerenciamento dos custos, a capacitação dos provedores e seus colaboradores, o cumprimento dos prazos etc. Outro aspecto que também tem influência na qualidade do atendimento ao cliente são as relações inter e intrapessoais, que determinam a necessidade do desenvolvimento de processos ligados a gestão de Recursos Humanos, visando à administração de conflitos, à necessidade de estímulos à motivação, dentre outros.

A implantação de processos de melhoria da qualidade no atendimento é um processo educacional, que extravasa as fronteiras das organizações, onde o primeiro passo é, desenvolver meios e métodos para conquistar e conservar o cliente. A busca pela qualidade se dá a partir da boa formação e gestão dos recursos humanos, da racionalização dos métodos de produção e do desenvolvimento tecnológico. Trata-se de uma realidade que não mais se constitui um modismo, tendo em vista todo o referencial teórico e as conseqüências que trazem para a prática da qualidade.

Portanto, para que a gestão do negócio turístico seja bem sucedida torna-se necessário a capacitação profissional dos trabalhadores envolvidos nos diferentes processos, principalmente, no processo de melhoria da qualidade do atendimento ao cliente. Isso deve ser visto como algo fundamental, urgente e necessário para toda e qualquer organização ligada ao negócio turístico, que pretenda manter-se e crescer no mercado. 


\section{REFERÊNCIAS}

AMARAL, Lincon. Turismo e Hotelaria, em 04/01/2003. Disponível em http://www.integral.br/zoom/materia.asp?materia=137. Busca em outubro de 2008.

BOYER, Marc. História do turismo de massa. Bauru-SP: EDUSC, 2003.

CALDAS, Rosângela Formentini. Novas tecnologias para uma nova educação. Disponível em http://cdchaves.sites.uol.com.br/novas_tecnologias.htm. Busca em julho de 2003.

CASTELLI, Geraldo. Turismo: atividade marcante. Caxias do Sul-RS: EDUCS, 2001.

CASTRO, Celso. Narrativas e imagens do turismo no Rio de Janeiro. Org. Velho, Gilberto. Rio de Janeiro: Zahar, 1999.

CC - CENTRAL DO CONSUMIDOR. Estatísticas Nacionais e Internacionais relevantes. Disponível em: http://centraldoconsumidor.blogspot.com.br/2010_01_01_archive.html. Busca em dezembro de 2012.

COOPER, C.; FlETCHER, J.; GILBERT, D.; WANHILl, S. e SHEPHERD, R. Turismo princípios e prática. Porto Alegre - RS: Artmed, 2001.

CORRÊA, Henrique L.; CAON, Mauro. Gestão de Serviços: Lucratividade por meio de operações e de satisfação dos clientes. São Paulo: Atlas, 2006.

CROSBY, Philip B. Qualidade é investimento: a arte de garantir a qualidade. 3.ed. Rio de Janeiro: J. Olympio, 1990.

FALCONI, Vicente. Controle de qualidade total: no estilo japonês. Belo Horizonte: Fundação Christiano Ottoni, 1992.

GIL, A. C. Métodos e técnicas de pesquisa social. São Paulo: Atlas, 2007.

HECKERT, Cristiano Rocha; SILVA, Márcia Terra da. Qualidade de serviços nas organizações do terceiro setor. Revista Produção, v. 18, n. 2, maio/ago. 2008, p. 319-330. Disponível em: <http://www.scielo.br/pdf/prod/v18n2/09.pdf>. Busca em novembro de 2012.

IGNARRA, L. R. Fundamentos do turismo. São Paulo: Thomson, 2003.

JURAN, J.M., GRYNA, Frank M. Controle da qualidade: conceitos, políticas e filosofia da qualidade. São Paulo: Makron Books, 1991.

JURAN, Joseph M. Juran planejando para a qualidade. São Paulo: Pioneira, 1990.

LOBOS, Julio. Encantando o Cliente. São Paulo: Instituto da qualidade, 1993. 
MASETTO M. Competências pedagógicas do professor universitário. São Paulo: Summus, 2003.

MATA, Maria Lutgarda. Revolução tecnológica e educação - Perspectiva da educação a distância. In LOBO NETO (org.) Educação a distância: referências e trajetórias. Rio de Janeiro. Assoc. Brasileira de Tecnologia Educacional, Brasília: Plano Editora, 2001, pág. 80.

NAKAMURA, Yoko. Revista Turismo - Turismo e Hotelaria, março de 2003, disponível em http://www.revistaturismo.com.br/materiasespeciais/profissionalizacao.htm.Busca out. 2008.

OMT - Organização Mundial do Turismo. Disponível em: http://www.unwto.org/index_s.php. Busca em dezembro de 2008.

. Turismo no mundo: Fluxo receptivo internacional. Disponível em http://www.dadosefatos.turismo.gov.br/dadosefatos/estatisticas_indicadores/estatisticas_basicas_t urismo/ . Busca em agosto de 2013.

PALADINI, Edson Pacheco. Gestão da qualidade: teoria e prática. São Paulo: Atlas, 2000.

PERRENOUD, P. Construir as Competências desde a Escola. São Paulo: Papirus, 2002.

PRETI, Oreste (org.). Educação a distância: construindo significados. Cuibá, MT. NEAD/IE UFMT. Brasília: Plano Editora, 2000.

RODRIGUES, J. L. K. (org.) Turismo o negócio do novo milênio. Taubaté - SP: Cabral Editora e Livraria Universitária, 2004.

RODRIGUES, J. L. K. (org.) Pesquisa realizada no Litoral Norte Paulista com organizações que atuam na área do turismo, 2010.

RODRIGUES, Jorge L. K. Reflexões sobre o docente no ensino superior brasileiro. Rio de janeiro: Corifeu, 2006.

SENGE, Peter. Escolas que aprendem: um guia da Quinta Disciplina para educadores, pais e todos que se interessam pela educação/ Peter Senge ... [et al.]; tradução Ronaldo Cataldo Costa. Porto Alegre -RS: Artmed, 2005.

TAGUCHI, Geniehi. Engenharia de Qualidade em Sistemas de Produção. São Paulo: Mc GrawHill, 1990.

TSCHOHL, John, FRANZMEIER, Steve. A Satisfação do Cliente: como alcançar a excelência através do serviço ao cliente. São Paulo: Makron Books, 1996.

VERGARA, S. C. Projetos de pesquisa em administração. São Paulo: Atlas, 2005. 
WALKER, Denis. O cliente em primeiro lugar: $\mathrm{O}$ atendimento e a satisfação do cliente como uma arma poderosa de fidelidade e vendas. São Paulo: Makron, 1991.

ZOUAIN, Deborah Moraes e Barbosa, Luiz Gustavo Medeiros, organizadores: gestão em turismo e hotelaria. São Paulo: Aleph, 2004. 